\title{
Do We Need to Change Our Antibiotic Prescription Practices?
}

\section{Uma $\mathrm{P}^{*}$}

Department of Obstetrics \& Gynecology, Banaras Hindu University, India

*Corresponding author: Uma Pandey, Department of Obstetrics \& Gynecology, Banaras Hindu University, Varanasi-221005, India, Tel: 00919793094060; Email: uma.pandey2006@yahoo.com

\section{Research Article \\ Volume 1 Issue 5}

Received Date: December 09, 2016

Published Date: December 21, 2016

\section{Abstract}

Objectives: To compare the postoperative outcome in patients group who were given single dose antibiotic prophylaxis to prolongedpostoperative antibiotic prescription.

Methods: Total 100 cases were included in this study. 50 cases (Group 1) were given one dose of prophylactic antibiotic (Cephalosporin and Metronidazole) while other group (Group 2) received postoperative antibiotic for seven days (Cephalosporin, Gentamicin and Metronidazole).Comparison was made between complications like fever, UTI, chest infection and secondary haemorrhage.

Results: The postoperative complications were $58 \%$ in seven-day course antibiotic group while it was $38 \%$ in the single day course. Urinary tract infection was the commonest infection in both groups $14-18 \%$. There was no wound dehiscence or burst abdomen in either of the group. There were no mortalities in either group as well.

Conclusion: Our study shows that single dose antibiotic is more effective to seven-day course. This study has small sample size to draw a firm conclusion; a randomized control trial in our set up would give us a better answer. If we strictly follow the single dose prophylaxis in our elective patients it might reduce the antibiotic resistance and/or economic burden on the health system.

Keywords: Antibiotic Prophylaxis; Operative Gynaecology; Post-Operative Infections; Morbidities

\section{Introduction}

Antibiotic prophylaxis is used all over the world to reduce the postoperative infection but one thing always questionable whether we are overusing the antibiotics in the postoperative period? Many a clinical practices are still using postoperative antibiotic for seven days. There is frequent change in the antibiotic molecule and also different modes of administration are used. Generally they are used form 5-7 days.

Excessive use of antibiotics can result in changed gut flora, antibiotic resistant bacteria, adverse reactions and extra cost [1].
Admission to the hospital itself predisposes the patient to infection by certain bacteria that are prevalent in the hospital called as nosocomial infection. Nearly 3-5 \% of the postoperative patients develop surgical site infection. This leads to increased cost and duration of stay for the patient [2].

Majority of the surgical procedures were emergency surgeries in the beginning of surgical practice. These procedures needed antibiotic prescription for 5-7 days. But, now a major proportion of surgeries are done on an elective basis and the surgical wounds are clean. These procedures need only single dose antibiotic [3]. 
Majority of the western set up hospitals do not use postoperative antibiotic. Studies have proven that antibiotic shot given just before the operative procedure is enough to maintain antibiotic level during operation. This is as effective as 5-7 days of postoperative antibiotic treatment $[4,5]$.

\section{Methods}

Data was collected retrospectively from the patients admitted to the ward for elective surgical procedure, retrospective observational study. The duration of the study was from July 2015 to Feb 2016.

Written informed consent was taken from patients and the institutional ethics committee approved study.

Total 100 cases were included in this study. 50 cases (Group 1) were given one dose of prophylactic antibiotic (Cephalosporin and Metronidazole) within one hour of surgery while other group (Group 2) received postoperative antibiotic for seven days (Cephalosporin, Gentamicin and Metronidazole). Group 2 received intravenous or intramuscular antibiotic for 24 hours, then they were switched on to oral Cephalosporin and Metronidazole while Gentamicin was given parenteral.

Those cases were excluded from the study group who were predisposed to infection i.e. known diabetics, patients with malignant condition, cardiac disease, chronic obstructive airway disease and hypertensive.

Performa was prepared and details were noted on that. Patient details like age, socioeconomic class, indication of surgery, $\mathrm{Hb} \%$ and $\mathrm{BMI}$ was noted. Baseline assessment was done inclusive of pulse, BP, temperature, respiratory rate, general exam, and also systemic exam, abdominal exam and gynaecological exam was recorded along with biochemical and haematological investigations.

Types of operation, total operative time, per operative complications and estimated blood loss were recorded.

The postoperative period was observed as per hospital protocol. Vitals were measured, chest exam, abdominal exam, perineal exam (in vaginal hysterectomy cases) was done in the postoperative period. Haematological investigation was done to assess the blood loss. If there was development of infection/pus then culture was done.

Postoperative complications were observed, investigated and managed e.g fever, chest infection, UTI, wound Infection, vaginal discharge, vault haematoma, secondary haemorrhage and wound dehiscence.

\section{Results}

Data was collected for 100 patients retrospectively, 50 belonged to the group who received single dose antibiotic (group 1) while the rest received seven day course (group 2) of antibiotic. The study duration was almost one year.

Abdominal hysterectomy was the commonest operative procedures (Graph 1) in both groups (44\% in single dose group and $54 \%$ in seven day course group (Graph 2)) followed by vaginal hysterectomy (28\% in group 1 and 32\% in group 2) (Table 1).

\section{Types of operation group}

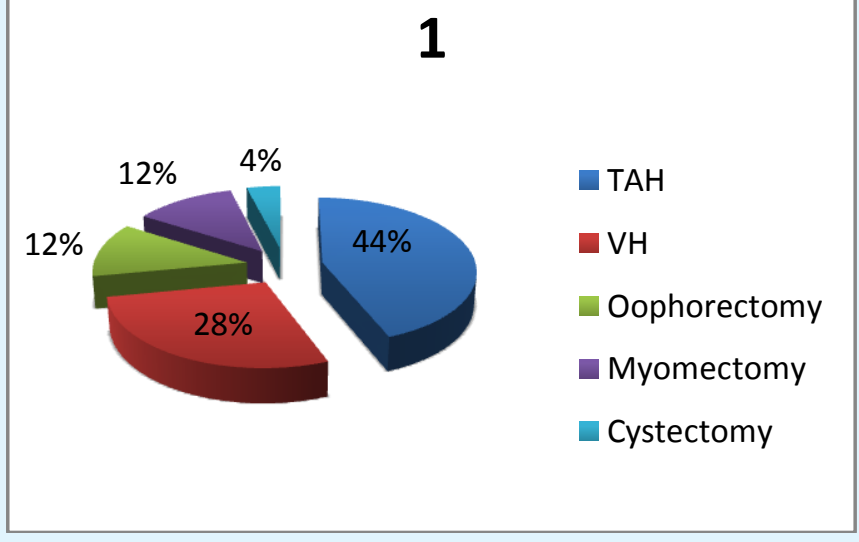

Graph 1: Showing types of operation in the group 1 study.

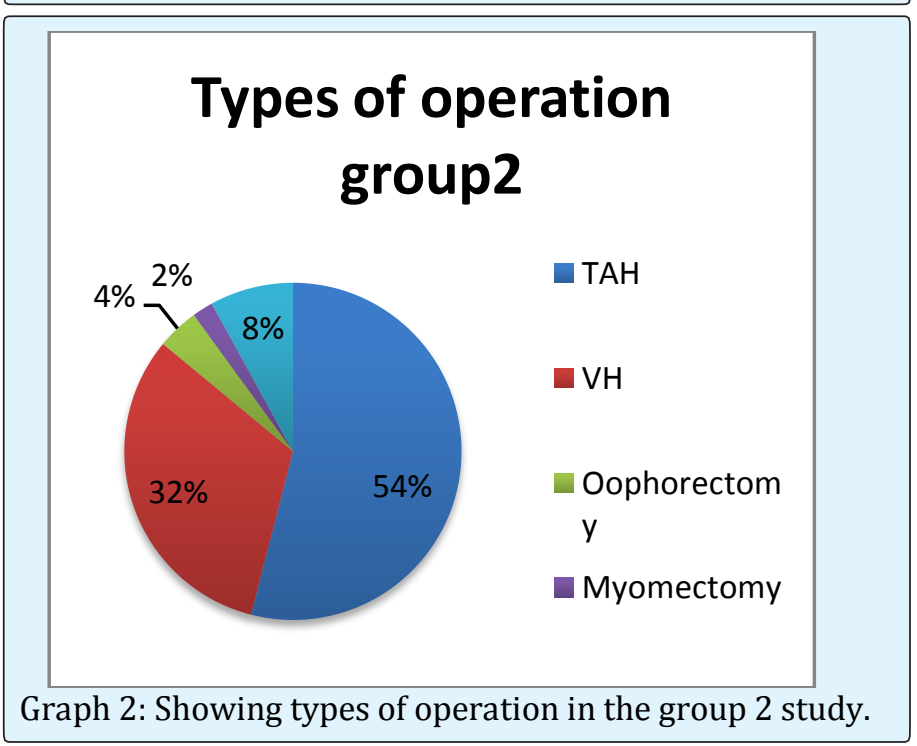




\begin{tabular}{|l|l|l|}
\hline $\begin{array}{l}\text { Types of } \\
\text { operation }\end{array}$ & $\begin{array}{l}\text { Group 1 } \\
\text { (single dose) } \\
\text { total } \\
\text { patients }\end{array}$ & $\begin{array}{l}\text { Group 2 (Seven } \\
\text { day course) } \\
\text { total } \\
\text { patients }\end{array}$ \\
\hline $\begin{array}{l}\text { Total Abdominal } \\
\text { Hysterectomy }\end{array}$ & $22(44 \%)$ & $27(54 \%)$ \\
\hline $\begin{array}{l}\text { Vaginal } \\
\text { Hysterectomy }\end{array}$ & $14(28 \%)$ & $16(32 \%)$ \\
\hline Oophorectomy & $6(12 \%)$ & $2(4 \%)$ \\
\hline Myomectomy & $6(12 \%)$ & $1(2 \%)$ \\
\hline Cystectomy & $2(4 \%)$ & $4(8 \%)$ \\
\hline
\end{tabular}

Table 1: Types of operation.

The mean age in the group 1 (single dose antibiotic group) was 42.59 while group 2 (seven day course antibiotic group) was 45.94 years (Table 2). There was just one-gram difference between both groups in Haemoglobin. BMI was almost similar in both groups. Mean duration of operation was 60 minutes in the group 1 , while it was 75 minutes in the group 2. Hospital stay was almost similar in both groups. There was $20 \mathrm{ml}$ of difference in the estimated blood loss between two groups (group 2 has relatively higher) (Table 2).

\begin{tabular}{|c|c|c|}
\hline Patient details & $\begin{array}{c}\text { Group 1 (total } \\
\text { 50) }\end{array}$ & $\begin{array}{c}\text { Group 2 (total } \\
\mathbf{5 0 )}\end{array}$ \\
\hline $\begin{array}{c}\text { Mean age (in } \\
\text { years) }\end{array}$ & 42.59 & 45.94 \\
\hline Mean Hb (gm\%) & 10.4 & 11.6 \\
\hline $\begin{array}{c}\text { Mean BMI } \\
\left(\text { Kg/mt }{ }^{2} \text { ) }\right.\end{array}$ & 22.4 & 23.3 \\
\hline Operative time & 60 minutes & 75 minutes \\
\hline $\begin{array}{c}\text { Hospital Stay } \\
\text { (days) }\end{array}$ & 7.6 & 7.8 \\
\hline EBL (ml) & $150 \mathrm{ml}$ & $170 \mathrm{ml}$ \\
\hline
\end{tabular}

Table 2: Patient \& Operative details.

The postoperative complications were $58 \%$ in sevenday course antibiotic group while it was $38 \%$ in the single day course. Urinary tract infection was the commonest infection in both groups $14-18 \%$. There was no wound dehiscence or burst abdomen in either of the group. There were no mortalities in either group as well (Table 3).

\begin{tabular}{|c|c|c|}
\hline & $\begin{array}{c}\text { Group 1 } \\
\text { (percentage) }\end{array}$ & $\begin{array}{c}\text { Group 2 } \\
\text { (percentage) }\end{array}$ \\
\hline Fever & $5 / 50(10 \%)$ & $6 / 50(12 \%)$ \\
\hline UTI & $7 / 50(14 \%)$ & $9 / 50(18 \%)$ \\
\hline Chest infection & $2 / 50(4 \%)$ & $4 / 50(8 \%)$ \\
\hline Wound & $4 / 50(8 \%)$ & $7 / 50(14 \%)$ \\
\hline
\end{tabular}

Uma P. Do We Need to Change Our Antibiotic Prescription Practices? J Gynecol 2016, 1(5): 000128.

\begin{tabular}{|c|c|c|}
\hline infection & & 0 \\
\hline $\begin{array}{c}\text { Wound } \\
\text { dehiscence }\end{array}$ & 0 & $3 / 50(6 \%)$ \\
\hline $\begin{array}{c}\text { Secondary } \\
\text { haemorrhage }\end{array}$ & $1 / 50(2 \%)$ & 0 \\
\hline Death & 0 & $29 / 50(58 \%)$ \\
\hline Total number & $19 / 50(38 \%)$ &
\end{tabular}

Table 3: Complications.

\section{Discussion}

Surgeon always tries to make sure that the wound infection in the postoperative period is minimal. There are various ways in which it can be done which includes personal hygiene of the patient, sterilization of equipments, ward cleanliness and surgeon' good surgical practices. Antibiotics were used for infection prophylaxis in 1960', which considerably reduced the wound infection rate or postoperative infection rate [6,7].

Judicious use of antibiotic resulted in reduction of infection, but later it became a human tendency to use it for almost any indication or in any situation. This human tendency led tooveruse, which has created even a bigger problem i. e. antibiotic resistance. With increasing antibiotic resistance there is an increased economic burden on the health budget $[8,9]$.

This comparative study in elective procedures shows that single dose antibiotic prophylaxis (group 1) is even better than seven-dose antibiotic course (group 2). The wound infection rate was $8 \%$ in group 1 while $14 \%$ in group 2. Similarly the incidences of fever, chest infection and UTI were also lower in group 1. Incidence of secondary haemorrhage was $2 \%$ in the group 1 while $6 \%$ in group 2, both group patients resolved spontaneously, without needing any operative intervention (Table 3).

Studies report that postoperative fever is approximately $32-52 \%$, being the commonest. In our study group 1 has 10\%, while group 2 had $12 \%$ [10].

\section{Conclusions}

Our study shows that single dose antibiotic is more effective to seven day course. This comparative study in elective procedures shows that single dose antibiotic prophylaxisis even better than seven-dose antibiotic course. The wound infection rate was $8 \%$ in group 1 while $14 \%$ in group 2 . Similarly the incidences of fever, chest infection and UTI were also lower in group 1. Incidence of 
secondary haemorrhage was $2 \%$ in the group 1 while $6 \%$ in group 2, both group patients resolved spontaneously, without needing any operative intervention.

This study has small sample size to draw a firm conclusion; a randomized control trial in our set up would give us a better answer.

We strictly follow single dose antibiotic in our elective patients' care and it is much better than seven days antibiotic course on many aspect (as described in result), therefore the author recommends single dose antibiotic in Elective cases and judicious use of antibiotic in emergency cases.

\section{Conflicts of Interest}

There is no conflict of interest. Study was ethically approved and consent was taken.

\section{References}

1. ACOG Committee on Practice Bulletins-Gynaecology (2009) ACOG practice Bulletin No 104: antibiotic prophylaxis for gynaecologic procedures. Obstet Gynecol 113(5): 1180-1189.

2. ACOG (2006) Antibiotic prophylaxis for gynaecolgic procedures. Obstetric Gynaecol 108: 225-234.

3. Dar LR, Farnaz F (1999) Prophylactic antibiotics in elective major gynecological surgery: single perioperative dose vs multiple postoperative doses. Mother and child 37: 51-53.
4. Puchades MS, Harrez-Vilas JM, Aytes LB, Gray-Ecoda C (2009) Antibiotic prophylaxis to prevent local infection in oral surgery: use or abuse? Med Oral Patol Oral Cir Bucal 14(1): 28-33.

5. Lotfi CJ, Caralcanti RC, Costa SA (2008) Risk factors for surgical site infection in head and neck cancer surgery. Otolaryngol Head Neck Surg 138(1): 74-80.

6. Tita AT, Rouse DJ, Blackwell S, Saade GR, Sponge CY, et al. (2009) Emerging concepts in antibiotic prophylaxis for caesarean delivery: a systemic review. Obstet Gynecol 113(3): 675-682.

7. Costantine MM, Rahman M, Ghulmiyah L, Byers BD, Longo M, et al. (2008) Timing of periperative antibiotics for caesarean delivery: a meta-analysis. Am J Obstet Gynecol 199(3): 301e1-e6.

8. Olsen MA, Nepple JJ, Riew KD, Lenke LG, Bridwell KH, et al. (2008) Risk factors for surgical site infection following orthopaedic spinal operations. J Bone Joint Surg Am 90(1): 62-69.

9. Imamura $\mathrm{H}$, Kurokana $\mathrm{Y}$, Tsujinaka $\mathrm{T}$, Inoue $\mathrm{K}$, Kimura $Y$, et al. (2012) Intraoperative versus extended antimicrobial prophylaxis after gastric cancer surgery: a phase 3 , open label, randomized controlled, non-inferiority trial. The Lancet Infectious Diseases 12(5): 381-387.

10. Schwandt A, Andrews SJ, Fanning J (2001) Prospective analysis of a fever evaluation algorithm after major gynaecologic surgery. Am J Obstet Gynaecol 184(6): 1066-1067. 